\title{
PATTERN OF METASTATIC BONE DISEASE- AN OBSERVATIONAL STUDY
}

\author{
Shalini Krishnan', Jayarama Shetty2, Gogineni Subhas Babu³, Rajeev T. P4
}

${ }_{1}^{1}$ Reader, Department of Oral and Maxillofacial Surgery, A. B. Shetty Memorial Institute of Dental Sciences, Mangalore.

2 Professor and HOD, Department of Oncology, K. S. Hegde Medical Academy, Mangalore.

3 Professor and HOD, Department of Oral and Maxillofacial Radiology, A. B. Shetty Memorial Institute of Dental Sciences, Mangalore. 4 Professor and HOD, Department of Urology, K. S. Hegde Medical Academy, Mangalore.

\section{BACKGROUND}

ABSTRACT

Metastasis to the skeletal system is commonly associated with lung, prostate and breast cancers. The pattern of metastatic spread varies depending on the type of the primary tumour and its site. This study aimed to assess the pattern and anatomical distribution of skeletal metastases in histologically proven malignancies.

\section{MATERIALS \& METHODS}

128 consecutive cancer patients with evidence of skeletal metastasis were evaluated for the anatomical distribution of bone metastases. The clinical presentation of the metastatic bone disease was documented and the pattern of skeletal metastasis in various cancers evaluated.

\section{RESULTS}

The 128 patients (76 males and 52 females) consisted of 45 patients (35.2\%) with lung cancer, 41 patients (32\%) with prostate cancer, 19 patients $(14.8 \%)$ with breast cancer, 9 patients $(7 \%)$ with gastrointestinal cancer, 7 patients $(5.5 \%)$ with renal cell carcinoma and other miscellaneous tumours in the remaining 7. Spine was found to be the most common site of skeletal metastasis (57.8\%), followed by pelvic bones (22.6\%) and ribs (14.8\%). Lung cancers metastasized to spine, pelvis, ribs, scapula, hume rus and sternum. Prostate and breast cancers had metastatic lesions in the spine, pelvis, ribs, scapula, femur, sternum, clavicle, and tibia. The clinical presentation varied from no specific symptoms to bone pain, neurological deficit and pathological fracture.

\section{CONCLUSION}

Bone metastasis has been found to occur in a predictable pattern. Thus, the knowledge of the usual pattern of metastasis in the commonly seen malignancies will enable the clinician to formulate a thorough work-up for the diagnosis and management of metastatic bone disease.

\section{KEYWORDS}

Metastasis, Cancer, Bone Disease, Skeletal.

HOW TO CITE THIS ARTICLE: Krishnan S, Shetty J, Babu GS, et al. Pattern of metastatic bone disease- an observational study. J. Evolution Med. Dent. Sci. 2018;7(10):1204-1208, DOI: 10.14260/jemds/2018/275

\section{BACKGROUND}

Metastasis to the skeletal system is commonly seen associated with lung, prostate and breast cancers. The pattern of metastatic spread varies depending on the type of the primary tumour and its site and so does the clinical presentation. Awareness of the usual pattern of metastasis in the commonly seen malignancies will help in early identification. In order to evaluate the pattern of skeletal metastases and their anatomical distribution in various malignancies, a study was conducted among patients admitted in the Oncology wing of a tertiary care hospital.

\section{MATERIALS \& METHODS}

This cross-sectional, observational study was carried out to evaluate the pattern and distribution of skeletal metastases in

'Financial or Other Competing Interest': None.

Submission 08-02-2018, Peer Review 19-02-2018,

Acceptance 23-02-2018, Published 05-03-2018.

Corresponding Author:

Dr. Rajeev T. $P$,

Professor and HOD,

Department of Urology,

K. S. Hegde Medical Academy,

Mangalore.

E-mail: rajeevtp@yahoo.com

DOI: $10.14260 /$ jemds $/ 2018 / 275$

\section{(c) (i)}

128 patients (76 males and 52 females) with histologically proven malignancy and radiologically proven metastatic bone disease. The clinical presentation of metastasis was documented. Computed tomography, magnetic resonance imaging and nuclear imaging by bone scintigraphy were the investigation tools used for evaluation of skeletal metastases, as a part of the diagnostic work-up for disease staging. The anatomical distribution of metastases was studied, and the results tabulated. Correlation of the site of the metastatic bone lesions to that of the primary tumour was evaluated.

\section{RESULTS}

Of the 128 patients, 45 patients (35.2\%) were diagnosed with lung cancer, 41 patients (32\%) had prostate cancer, 19 patients $(14.8 \%)$ had breast cancer, 9 patients $(7 \%)$ had gastrointestinal cancer and 7 patients $(5.5 \%)$ had renal cell carcinoma. (Table 1) In the remaining 7 patients (5.5\%), the diagnosis varied and was hence classified into a miscellaneous group consisting of ovarian cancer, hepatocellular cancer, cancer of the oropharynx, metastatic leiomyosarcoma, hepatocellular cancer, thyroid cancer and one patient with an unknown primary. The patients belonged to the age range of 28 to 84 years (mean of $59.41 \pm 12.51$ ).

The sites of bony metastases were divided into spine, pelvic bones including sacroiliac joints and sacrum, ribs, skull, sternum, scapula, clavicle, humerus, femur, and tibia. Spine 
was found to be the most common site of skeletal metastasis (57.8\%), followed by pelvic bones including sacroiliac joints and sacrum (22.6\%) and the ribs (14.8\%). (Table 2) Out of 128 patients, 113 patients with skeletal metastasis were symptomatic, of which, 105 patients had bone pain and 8 patients complained of lower limb weakness associated with spinal metastasis. In thirteen patients with bone pain, metastatic bone lesion was associated with pathological fracture. (Table 3). In lung and prostate cancer patients, spine was found to be the most common site of metastasis followed by pelvis and ribs. In breast cancer patients, femur was noted as the third most common site of bone metastases. (Table 4).

\begin{tabular}{|c|c|}
\hline Site of Primary Tumour & Number of Patients \\
\hline Lung & 45 \\
\hline Prostate & 41 \\
\hline Breast & 19 \\
\hline Gastrointestinal tract & 9 \\
\hline Kidney & 7 \\
\hline Miscellaneous & 7 \\
\hline Total & 128 \\
\hline \multicolumn{2}{|c|}{$\begin{array}{c}\text { Table 1. Frequency distribution of primary tumour } \\
\text { according to site }\end{array}$} \\
\hline
\end{tabular}

\begin{tabular}{|c|c|}
\hline Site of Metastasis & Frequency \\
\hline Spine & 74 \\
\hline Pelvis & 30 \\
\hline Ribs & 19 \\
\hline Skull & 16 \\
\hline Femur & 12 \\
\hline Scapula & 9 \\
\hline Humerus & 8 \\
\hline Sternum & 7 \\
\hline Clavicle & 5 \\
\hline Others & 5 \\
\hline Table 2. Frequency distribution of site of skeletal \\
\multicolumn{2}{|c|}{ metastasis } \\
\hline
\end{tabular}

\begin{tabular}{|c|c|}
\hline Clinical Presentation & Number of Patients \\
\hline Bone pain & 105 \\
\hline $\begin{array}{c}\text { Bone pain with Pathological } \\
\text { fracture }\end{array}$ & 13 \\
\hline Neurological deficits & 8 \\
\hline No specific symptoms & 15 \\
\hline Table 3. Relation of clinical presentation with metastatic \\
bone involvement \\
\hline
\end{tabular}

\begin{tabular}{|c|c|c|c|c|c|c|c|c|c|c|}
\hline \multirow{2}{*}{$\begin{array}{l}\text { Site of } \\
\text { Primary }\end{array}$} & \multicolumn{10}{|c|}{ Anatomical Site } \\
\hline & Spine & Pelvis & Ribs & Skull & Femur & Scapula & Humerus & Sternum & Clavicle & Tibia \\
\hline $\begin{array}{l}\text { Lung } \\
(45)\end{array}$ & $\begin{array}{c}27 \\
(60 \%)\end{array}$ & $\begin{array}{c}9 \\
(20 \%)\end{array}$ & $\begin{array}{c}6 \\
(13.3 \%)\end{array}$ & $\begin{array}{c}2 \\
(4.4 \%)\end{array}$ & (2) & $\begin{array}{c}1 \\
(2.2 \%)\end{array}$ & $\begin{array}{c}2 \\
(4.4 \%)\end{array}$ & $\begin{array}{c}2 \\
(4.4 \%)\end{array}$ & 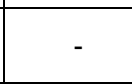 & - \\
\hline $\begin{array}{c}\text { Prostate } \\
\text { (41) }\end{array}$ & $\begin{array}{c}22 \\
(53.7 \%)\end{array}$ & $\begin{array}{c}15 \\
(36.6 \%)\end{array}$ & $\begin{array}{c}7 \\
(17.1 \%)\end{array}$ & $\begin{array}{c}4 \\
(9.7 \%)\end{array}$ & $\begin{array}{c}5 \\
(12.2 \%)\end{array}$ & $\begin{array}{c}6 \\
(14.6 \%)\end{array}$ & $\begin{array}{c}2 \\
(4.9 \%)\end{array}$ & $\begin{array}{c}4 \\
(9.7 \%)\end{array}$ & $\begin{array}{c}2 \\
(4.9 \%)\end{array}$ & $\begin{array}{c}1 \\
(2.4 \%)\end{array}$ \\
\hline $\begin{array}{c}\text { Breast } \\
\text { (19) }\end{array}$ & $\begin{array}{c}14 \\
(73.7 \%)\end{array}$ & $\begin{array}{c}8 \\
(42.1 \%)\end{array}$ & $\begin{array}{c}4 \\
(21 \%)\end{array}$ & $\begin{array}{c}4 \\
(21 \%)\end{array}$ & $\begin{array}{c}5 \\
(26.3 \%)\end{array}$ & $\begin{array}{c}1 \\
(5.3 \%)\end{array}$ & $\begin{array}{c}3 \\
(15.8 \%)\end{array}$ & $\begin{array}{c}2 \\
(10.5 \%)\end{array}$ & $\begin{array}{c}1 \\
(5.3 \%)\end{array}$ & $\begin{array}{c}1 \\
(5.3 \%)\end{array}$ \\
\hline
\end{tabular}

\section{DISCUSSION}

The term 'metastasis' basically describes a migration of tumour cells via the blood, or lymph into other primarily unaffected areas of the body. ${ }^{1}$ This process involves invasion of the lymphatics, blood vessels and body cavities by the tumour, followed by transport and growth of secondary tumour cell masses that are discontinuous with the primary tumour. Haematogenous spread is the route of metastasis in sarcomas but also the favoured route for carcinomas. Veins are more frequently invaded than arteries due to their thinner walls. Lung and liver are common sites of haematogenous metastases as they receive the systemic and venous outflow, respectively. Other major sites of haematogenous spread include brain and bones. ${ }^{2}$ Thus the term 'bone metastasis' describes the appearance of secondary tumours in the skeletal system after groups of tumour cells enabled to leave the primary tumour have reached the skeletal system. ${ }^{3}$

The varying nature and ability of metastases from different tumours suggests that cells within a primary tumour are heterogenous with respect to metastatic abilities and only certain subclones can complete all the steps in the metastatic cascade to form secondary tumours at distant sites. This can be exemplified by the propensity of osteogenic sarcomas to develop metastases early in their course than salivary gland carcinomas. The tumour cells must attach to, degrade and penetrate the basement membrane and interstitial connective tissue of the extracellular matrix to enable tumour migration. In the circulation these tumour cells form emboli by aggregation and by adhering to leukocytes, particularly platelets. The site where tumour cell emboli lodge and produce secondary growth is influenced by the vascular and lymphatic drainage from the site of the primary tumour, interaction of tumour cells with organspecific receptors and microenvironment of the organ or site of distant metastasis. ${ }^{2}$

Bone is the third most common site for metastasis after lung and liver. It is one of the most common sites for metastasis in patients with solid tumours arising from breast, prostate, lung, thyroid, kidney and bladder. 4 Other tumours that can metastasize to bone include melanoma, neuroblastoma, hepatocellular carcinoma, carcinoid tumour, paraganglioma and few other solid tumours.

The propensity for cancer cells to metastasize to bone and to induce osteolysis has long been recognized. Characteristics of both the tumor cells and the bone microenvironment contribute to this phenomenon. The presence of tumor in bone is associated with activation of osteoclasts, resulting in excessive bone resorption and subsequent osteolysis. Breast cancer cells and other tumor types influence osteoclastic bone resorption by increasing the number of osteoclasts and enhancing their resorptive activity. Parathyroid hormonerelated peptide (PTHrP), in addition to its role in humorally 
mediated hypercalcemia, is secreted by metastatic breast cancer cells in bone in which it acts as a paracrine factor to stimulate osteoclasts. As bone matrix is broken down by activated osteoclasts, a rich supply of mitogenic factors is released, including insulin-like growth factors, bone morphogenetic proteins, and fibroblast growth factors. Transforming growth factor (TGF)-beta, one of the most abundant of the bone-derived factors, promotes increased production of parathyroid hormone-related peptide by tumor cells, establishing a "vicious cycle" leading to progressive tumor growth and bone destruction. Bisphosphonates interrupt this cycle by inhibiting osteoclasts, in part by inducing osteoclast apoptosis. ${ }^{5}$

Approximately $70 \%$ of patients with advanced breast or prostate cancer, and upto $40 \%$ of patients with other advanced solid tumours, develop bone metastases over the course of their disease. More than $50 \%$ of advanced prostate cancer cases and $20 \%$ of advanced breast cancer cases have metastatic disease clinically confined to the skeleton. ${ }^{6}$

Development of skeletal metastases from a solid tumour usually means that the disease has a poor prognosis and the management is usually palliative. The median survival after the diagnosis of bone metastasis ranges from 3-6 months in non-small cell lung cancer to 53 months in prostate cancer. ${ }^{7}$

The variability in metastatic patterns of cancer is influenced by the molecular and cellular characteristics of both the tumour cells and the tissues to which they metastasize. Bone metastases most commonly affect the axial skeleton owing to the physical properties of the circulation within the bone marrow, including capillary structure and sluggish blood flow, which assists in the establishment of metastases. $^{7}$

The most common sites of bone metastases are the spine, femur and skull. Metastases reach the skeleton in different ways through the vascular system and are thus dependent on the blood supply of the primary tumour. Early metastases in the pelvis and the lumbar vertebrae are typical in prostate cancer. Here, the metastatic disease spreads cranially via a paravertebral vascular network, called 'Batson's plexus'.

The most common sites for metastatic breast cancer to bone are spine, pelvis, ribs, skull, femur, humerus, and scapula. Metastases from thyroid cancer are more commonly located in the 'flat' bones, scapula, pelvis, skull, ribs or sternum. Metastases in the fingers, especially the distal phalanx-acrometastases are extremely rare, but arise most commonly from a cancer of the lung, kidneys or breast. ${ }^{3}$

Skeletal involvement by metastatic disease can be classified as osteolytic, osteoblastic or mixed, based on the radiographic findings. 6 Metastases from prostate cancer are usually osteoblastic, but lytic and mixed lesions may also be seen. Predominantly osteolytic metastases occur typically in thyroid cancer, lung cancer, renal cell cancer and cancers of the gastrointestinal tract. Metastatic breast cancer to the bone can be purely lytic, or mixed lytic and blastic. ${ }^{8}$

Distant metastasis from oral cancer is associated with advanced stage. Gingiva has been found to be the most frequent primary site associated with distant metastasis. Skeletal metastasis to different bones has been reported with a higher incidence to vertebral bones. ${ }^{9}$

Metastasis to the orofacial region is uncommon, comprising only $1-3 \%$ of all malignant oral neoplasms, and may occur in the jawbones or oral soft tissues. Clinical presentation of metastatic lesions can be variable, and can lead to misdiagnosis or create a diagnostic dilemma. The common primary tumours metastasizing to the oral cavity are the breast, lung and kidney. Mandible is the most common site and the molar region is found to be the most frequently involved area. ${ }^{10}$

The pathogenesis of metastatic tumours in the jawbones is not clear. Within the skeleton, bones with red marrow are the favoured sites for metastatic deposits. Remnants of hematopoietic active marrow can be detected in the posterior areas of the mandible, which attract metastatic tumour cells. Moreover, the oral soft tissues have a rich network of capillaries, which can attract malignant cells. ${ }^{10}$

Malignant tumours metastasize according to predictable patterns. Several theories have been proposed to explain this tumour behaviour, including the Paget's 'seed and soil hypothesis' and Ewing's hypothesis.11 An English surgeon, Stephen Paget in 1889, proposed the seed and soil hypothesis. He proposed that the processes of metastasis did not occur by chance; certain tumour cells with metastatic potential (the 'seed') have a special affinity for the growthenhancing milieu within specific organs (the fertile 'soil'). He suggested that metastases developed only when the seed and soil were compatible.12 In other words, development of a metastatic lesion in a particular site depended on the favourable microenvironment provided by that organ. This theory is still relevant today, although different factors involved in the attraction and subsequent growth of tumour cells have been discovered, such as accumulation of genetic changes within cancer cells, preferential binding of cancer cells to bone marrow endothelial cells, and the release of cancer cell chemoattractants from bone elements. ${ }^{13}$

Ewing's theory suggests that metastatic deposits are primarily a mechanical phenomenon. Cancer cells are directed to a specific site by the direction of the blood flow and lymphatics. Ewing's theory accounts for cancer growth in the draining lymph nodes and liver, but Paget's theory describes distal metastases that are organ-specific. ${ }^{13}$ However, Ewing's theory does not explain the observation that some organs such as brain, bone and adrenals receive a very small fraction of the circulatory system, yet are often involved in metastatic deposits of certain cancers. On the other hand, organs such as heart, muscle, skin, kidney and spleen, which receive a considerable supply of blood, are rarely colonized by metastatic cancers. ${ }^{12}$

Isaiah Fidler in 2002 redefined the modern 'seed and soil' hypothesis as three principles. First, cancerous cells contain heterogenous subpopulations of cells with differing angiogenic, invasive and metastatic properties. Second, selective cells survive the long journey to a distal organ. Third, the success of the metastatic cells depends on the ability of these cells to interact and utilize the 'soil' provided by the new microenvironment. 13

Many of the steps in cancer metastasis involve changes in cell adhesion to adjacent cells and to the extracellular matrix. The cell surface receptor integrins have been implicated in mediating the interactions of prostate cancer cells within their microenvironment. Changes in integrin expression have been documented in primary prostate tumours and prostate cancer cell lines. Prostate cancer cells cross the surrounding stroma, and enter the microvasculature by intravasation. In the circulation, the ability of the cancer cells to adhere to and 
aggregate with platelets through the expression of cell surface receptors may protect them from shear forces of blood flow. Prostate cancer cells have been shown to preferentially bind directly to bone marrow endothelial cells three- to five-fold more than to aortic or dermal vascular endothelial cells. This 'locking' of prostate cancer cells to endothelial cells is facilitated through the complex collaboration of integrins. ${ }^{13}$

It has been pointed out that common regional metastatic involvements could be attributed to anatomical or mechanical considerations, such as afferent venous circulation or lymphatic drainage to regional lymph nodes, but metastasis to distant organs by metastatic cells from various cancers had a different pattern of site specificity. ${ }^{14}$ This has been demonstrated in patients with incurable abdominal ascitic cancer treated with peritoneal-venous shunting; despite a large number of tumour cells directly infused into the circulation, many patients did not develop evident metastases and among those who did, the metastases did not form in the organ containing the first capillary bed encountered, although haematogenous metastases had formed in other organs. ${ }^{15}$

In an experimental study on transplanted tumour cells in mice, it was found that the number of metastases is directly proportional to the number of viable tumour cell emboli released and also to the duration of growth of the primary tumour. ${ }^{16}$

It has also been observed that the distribution of metastases is largely dependent on mechanical factors such as the arrest of emboli in capillaries of secondary organs where metastases are more commonly seen, compared to those rare sites of metastases where circulating cells are seen to be lodged in arterioles. The incidence of the arrest is seen to vary with the type of tumour.17,18 $\mathrm{A}$ larger number of liver metastases is seen compared to lung, which suggests that both mechanical and local 'soil' factors are likely to determine the development of a metastatic lesion after the arrest of tumour emboli. ${ }^{19}$ Thus, the development of secondary lesions is influenced by the specific organ cells.

Metastasis favours the survival and growth of a few subpopulations of cells that pre-exist within the parent neoplasm. Hence, metastases can have a clonal origin, and different metastases can originate from the proliferation of different single cells. ${ }^{20}$ Cells with different metastatic properties have been isolated from the same parent tumour, indicating that not all the cells in a primary tumour have the same potential to disemminate. ${ }^{11} \mathrm{~A}$ new theory explains the relationship between the primary and metastatic sites as a bidirectional pathway, rather than unidirectional. According to this theory, the surviving cancer cells in the secondary tumour site have the ability to return to the primary site to accelerate the primary tumour progression. This process is known as 'self-seeding' wherein, the metastatic process is multidirectional, and the cancer cells can seed distal sites as well as the primary tumour itself. ${ }^{21}$

Apart from the 'organ selection' theory, 'adhesion theory' and 'chemoattraction theory', a recently suggested concept is the formation of a metastatic niche. According to this concept, prior to colonization, the primary tumour induces the remodeling of an organ microenvironment by circulating tumour cells (CTCs). Then, a metastatic niche is produced to support disseminated tumour cells (DTCs) to localize them. A metastatic niche is a microenvironment that supports and facilitates the invasion and growth of metastasis. ${ }^{22,23}$

\section{CONCLUSION}

Metastasis to bone occurs in a predictable pattern. Knowledge of the usual pattern of metastasis in the commonly seen malignancies will enable the clinician to formulate a thorough work-up for the diagnosis and management of metastatic bone disease.

Bone metastases is associated with significant morbidity due to the intractable bone pain, reduced mobility, pathological bone loss and fractures, spinal compression and sequelae related to hypercalcemia, which is grouped under the term 'skeletal related events'. Owing to the increased prevalence of malignancy, prevention and management of the skeletal metastases is a major challenge. Over the years, several developments in the field of oncology, has dramatically changed the course of the disease and improved the survival and quality of life of these patients who were once considered incurable. The advances in the imaging modalities and the knowledge of pattern of skeletal metastases, help in early detection of metastatic disease so that aggressive therapeutic regimens are instituted even in Stage IV disease.

\section{REFERENCES}

[1] Barrett KE, Boitano S, Barman SM, et al. Hormonal control of calcium metabolism and the physiology of bone. Chap- 21. In: Ganong WF. Review of medical physiology. 19 $19^{\text {th }}$ edn. United States of America: Appleton \& Lange 1999:365-77.

[2] Robbins SL, Cotran RS, Kumar V. Neoplasia. Chap- 6. Robbins pathological basis of disease. India: WB Saunders 1991:105-24.

[3] Schirrmeister H, Arslandemir C. Diagnosis of skeletal metastases in malignant extraskeletal cancers. In: Heymann D. Bone cancer. Progression and therapeutic approaches. $1^{\text {st }}$ edn. Elsevier 2010:283-94.

[4] Coleman RE, Rubens RD. Bone metastases. In: Abeloff MD, Armitage JO, Niederhuber JE, et al, eds. Clinical oncology. $3^{\text {rd }}$ edn. New York: Churchill Livingstone 2004:1091-128.

[5] Mundy GR, Yoneda T, Hiraga T. Preclinical studies with zoledronic acid and other bisphosphonates: impact on the bone microenvironment. Semin Oncol 2001;28(2 Suppl 6):35-44.

[6] Tang P, Hicks DG. The histopathology of skeletal metastases. In: Heymann D. Bone cancer. Progression and therapeutic approaches. $1^{\text {st }}$ edn. Elsevier 2010:243-9.

[7] Coleman RE. Metastatic bone disease: clinical features, pathophysiology and treatment strategies. Cancer Treat Rev 2001;27(3):165-76.

[8] James JJ, Evans AJ, Pinder SE. Bone metastases from breast carcinoma: histopathological-radiological correlations and prognostic features. $\mathrm{Br} \mathrm{J}$ Cancer 2003;89(4):660-5.

[9] Irani S. Distant metastasis from oral cancer: a review and molecular biologic aspects. J Int Soc Prev Community Dent 2016;6(4):265-71. 
[10] Kumar G, Manjunatha B. Metastatic tumors to the jaws and oral cavity. J Oral Maxillofac Pathol 2013;17(1):71-5.

[11] Kakhi VR, Anvari K, Sadeghi R, et al. Pattern and distribution of bone metastases in common malignant tumors. Nucl Med Rev Cent East Eur 2013;16(2):66-9.

[12] Ribatti D, Mangialardi G, Vacca A. Stephen Paget and the 'seed and soil' theory of metastatic dissemination. Clin Exp Med 2006;6(4):145-9.

[13] Tantivejkul K, Kalikin LM, Pienta KJ. Dynamic process of prostate cancer metastasis to bone. J Cell Biochem 2004;91(4):706-17.

[14] Sugarbaker EV. Cancer metastasis: a product of tumour-host interactions. Curr Probl Cancer 1979;3(7):1-59.

[15] Tarin D, Price JE, Kettlewell MGW, et al. Mechanisms of human tumor metastasis studied in patients with peritoneovenous shunts. Cancer Res 1984;44(8):3584-92.

[16] Zeidman I, McCutcheon M, Coman DR. Factors affecting the number of tumour metastases; experiments with a transplantable mouse tumour. Cancer Res 1950;10(6):357-64.
[17] Coman DR, deLong RP, MccUtcheon M. Studies on the mechanism of metastasis: the distribution of tumours in various organs in relation to the distribution of arteriolar emboli. Cancer Res 1951;11(8):648-51.

[18] Zeidman I, Buss JM. Transpulmonary passage of tumour cell emboli. Cancer Res 1952;12(10):731-3.

[19] Luke B, Breedis C, Woo ZP, et al. Differential growth of metastatic tumors in liver and lung: expression with rabbit V2 carcinoma. Cancer Res 1952;12(10):734-8.

[20] Fidler IJ. Critical factors in the biology of human cancer metastasis: twenty-eighth G.H.A. Clowes memorial award lecture. Cancer Res 1990;50(19):6130-8.

[21] Comen E, Norton L, Massagué J. Clinical implications of cancer self-seeding. Nat Rev Clin Oncol 2011;8(6):369377.

[22] Psaila B, Lyden D. The metastatic niche: Adapting the foreign soil. Nature Rev Cancer 2009;9(4):285-93.

[23] Erler JT, Bennewith KL, Cox TR, et al. Hypoxia-induced lysyl oxidase is a critical mediator of bone marrow cell recruitment to form the premetastatic niche. Cancer Cell 2009;15(1):35-44. 